\title{
Electrical and optical properties of rf-sputtered CdTe films
}

\author{
P C SARMAH' and A RAHMAN" \\ Department of Physics, Gauhati University, Guwahati 781014, India \\ "Regiona] Research Laboratory, Jorhal 785 006, India \\ MS received 5 May 1997; revised 17 February 1998
}

\begin{abstract}
Absiract. In this paper some electrical and optical properties of $n$-type CdTe films prepared by rf sputtering at $180 \mathrm{~W}$ power have been reported. For doping the films a number of peltets of pure Cd placed on the CdTe target were simultaneously sputtered with the target material to gel Cd-doped CdTe lilms. The films after doping were found $n$-type. Maximum doping concentration obtained this way was of the order of $10^{14}$ $\mathrm{cm}^{-3}$. XRF spectra of target material and the rf-sputtered films were found to he more or less sinuilar. All the lilins were found to have large number of defects indicated lyy profound aging effect in the initial stages of aging. The films became stable for measurements after about 8 -10 days. Activation energy and band gap found from the temperature dependence of dark conductivity were $0.5 \mathrm{eV}$ and $1.43 \mathrm{eV}$ respectively. Photoconductivity of the filnos was studied and the photoconductive rise time, decay time and the decay constants were determined from the photoconductive rise and decay curves at $500 \mathrm{Lx}$ and $1000 \mathrm{Lx}$ of intensity of illumination.
\end{abstract}

Keywords Rf-sputtered lim; doping; ageing effect; activation energy; photoconductive decay.

\section{Introduction}

Studies of CdTe thin filns have received mucli attention for their various probable epplications. This zinc blende type semiconductor (Rose et al 1987) having a direct band gap $(-1.46 \mathrm{eV})$, is thought to be a promising candidate for thin film solar cell and other electro-optical devices. This is the only semiconductor of II-VI groups showing both types of conductivity (Zanio et al 1978).

Different techniques to prepare CdTe films to study their characteristics have been adopted by different workers. Some of them are vacuum deposition (Uda et al 1978), closed-space vapour trausport and closed-space sublimation (Mitchell et al 1985), electrodeposition (Basol 1988), sintered films (Matsumoto et al 1984), spray pyrolysis (Banerjee et al 1989), ff-sputtering (Das and Cook 1988) etc. The main advantage of if-sputtering is that stoichiometry of the sputtered material is retained in the deposited film (Fisher and Weber 1952), making it a suitable technique for depositing intermetallic compounds.

Many workers studied structural, electrical and optical properties of CdTe films prepared by rf-sputtering. Some of the properties studied by us have already been published earlier (Sarmah and Rahman 1950). Some unpublished works such as XRF studies, temperatute dependence of resistivity, aging elfect on resistivity and photoconductive rise and decay characteristics are presented in this paper.

\footnotetext{
*Author for comespondence
}

\section{Experimental}

CdTe films were prepared by rf-sputtering in an argon ion atmosphere as reported in our earlier paper (Sarmal and Rahman 1990). In order to prepare Cd rich films, pellets of endmium were fixed on the target to sputter simultaneously along with the target material. The rf power was maintained at $180 \mathrm{~W}$ in preparing all the samples. Two types of samples: gap-type and sandwich type, were prepared lor electrical measurements. In gap type samples, indium was vacuum deposited on the two ends of rectangular CdTe films for electrodes. Sandwich type samples were prepared by depositing indium film before and after the deposition of CdTe films. Indium was found to make ohmic contact with n-type CdTe film. The work function of indium has been reported to be $3.97 \mathrm{eV}$ (Rhoderik 1978) and that of CdTe to be $>4 \mathrm{eV}$ (Sheer and Laar 1961), which satisty the condition for making ohmic contact between them. For compositional analysis of rf-sputtered CdTe films: XRF spectra were taken with the help of a Philips pw-1480 spectrometer. For studying different characteristics of the samples in dark and under illumination, experiments were carried out in a specially designed apparatus as shown in figure 1. The apparatus consisted of two coaxial cylinders, the inner one being supported by the outer one, The outer cylinder has a side tube filted with an air tight window. The sample holder with the sample in it was vertically clamped to the outer sutface of the inner cylinder so that the sample faced the glass window. Shielded wires from the pressure contacts to the vacuum 
deposited electrodes and thernocouple wites were brought out of the chamber through feedthroughs. A cylindrical beater was placed inside the inner cylinder whose temperature was controlled by a temperature controljer (Philips-1.D 30). An X-Y recorder (Digital Electronics Ltd) was used for the purpose of measurements. For taking $I-V$ curves the bias voltage was given from a variable ramp (Systronic, model 1014). For photoconductive rise and decay, a constant voltage was applied to the sample through a standard resistance and was connected to the $X-Y / L$ recorder. The voltane applied to the sample was connected to the $X$-axis of the recorler and the potential drop across the standard resistance due to the current flowing through the sample was connected to the $\mathrm{Y}$-axis of the recorder. The anrular space between the two co-itxial cylinders was evacuated to aboul $10^{-8}$ torr by a roway pump before taking any measuremunt.

\section{Results and discussion}

We have reported XRD studies in an earlier paper (Samah and Rahman 1990) and showed that the CdTe films prepared at lower if power were amotphous and those prepared at higher power polycrystatine in narure. We have also observed that when the film was doped with In or $\mathrm{Cd}$ during sputtering, the film became more disordered (though not amotphous) even at higher power, compared to intriusic film prepared at the same of power. XRF spectra of target miterial and the if-sputtered films were also taken to know the compositions and quality of films. Three typicel XRF spectra are shown in figtre 2 for comparison.

\subsection{Aging effect}

These rf-sputtered films were always endowed with defects during deposition. With time some defects are Jikely to heal up due to jonic movements and as such film resistivity decreases showing aring effect. For the purpose of observing aging effect, resistivity of ifsputtered Cd-doped films was measured at room tetnperature after different intervals of time. The resistivity was found to decrease rapidly in the initial stage of aging and then at slower rate approaching a saturation value after several doys as show in figure 3 for two typical samples. Such aging effect has also been reported by earlicr workers (Gogoi and Barua 1982),

\subsection{Activation energy and band gap}

Temperature variation of conductivity of two typical Cr-doped CdTe films has becn shown in figure 4. Both gap-type and sandwich-type samples exhibit similar behaviour except a slight shifting in conductivity value. This difference in conductivity of two types of samples may be attributcd to the difference in thickness of the CaTe films. The thickness monsured by interference method was taken for calculation of conduclivity. But, obviously, in sandwich structure, the cffective thickness was reduced due to penetration of cotnter elcotrode materials while in gap type samples thickness was not affecled. I-Iowever, the temperature dependence plots for both types of samples are parallel giving same activation cnergies.

The ativation energy obtained from the slope at lower

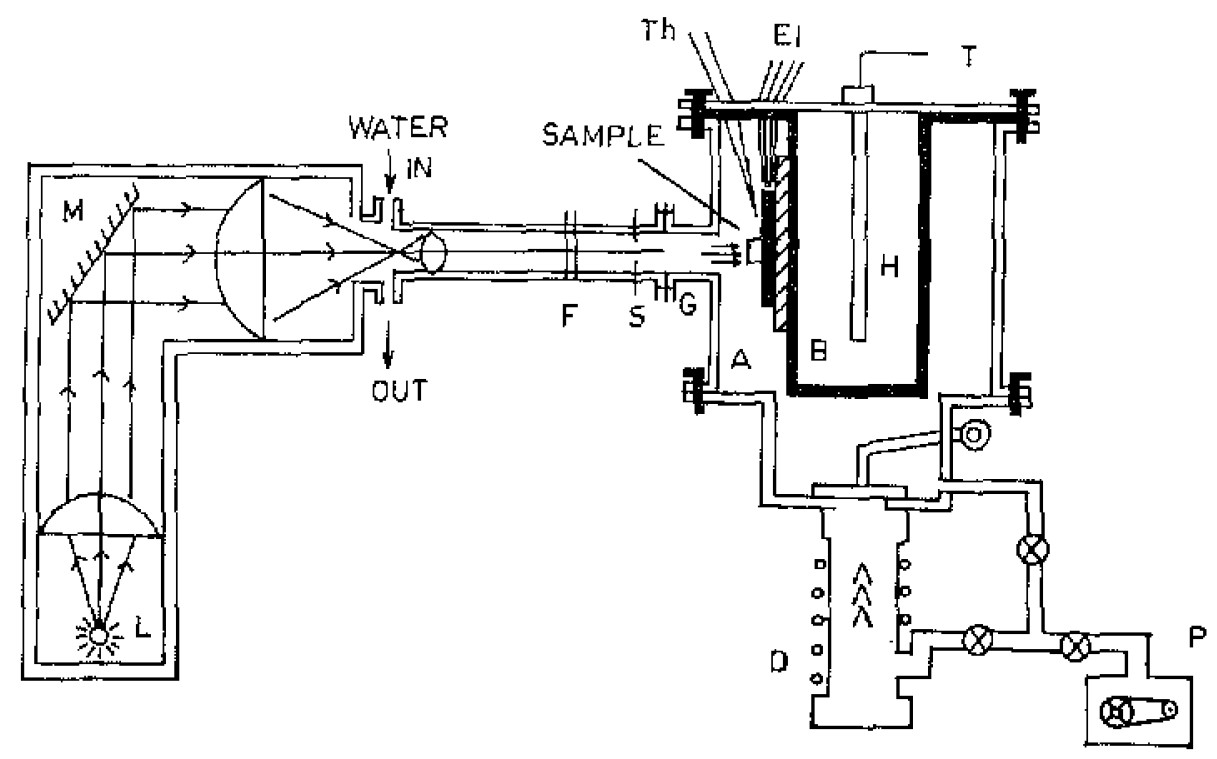

Fïgure 1. Experimental alrangement for diflercut measurements (L, light source: $M$, mirror, $A$, outer cylinder; $B$, inner cylinder; $G$, glass window; 5 , shutter; $F$, arrangement for ijIters; Th, thermoconple; El, electrodes; $\mathrm{H}$, heater; T, temperature controller; D, diffusion pump; $P$; rotary pump). 

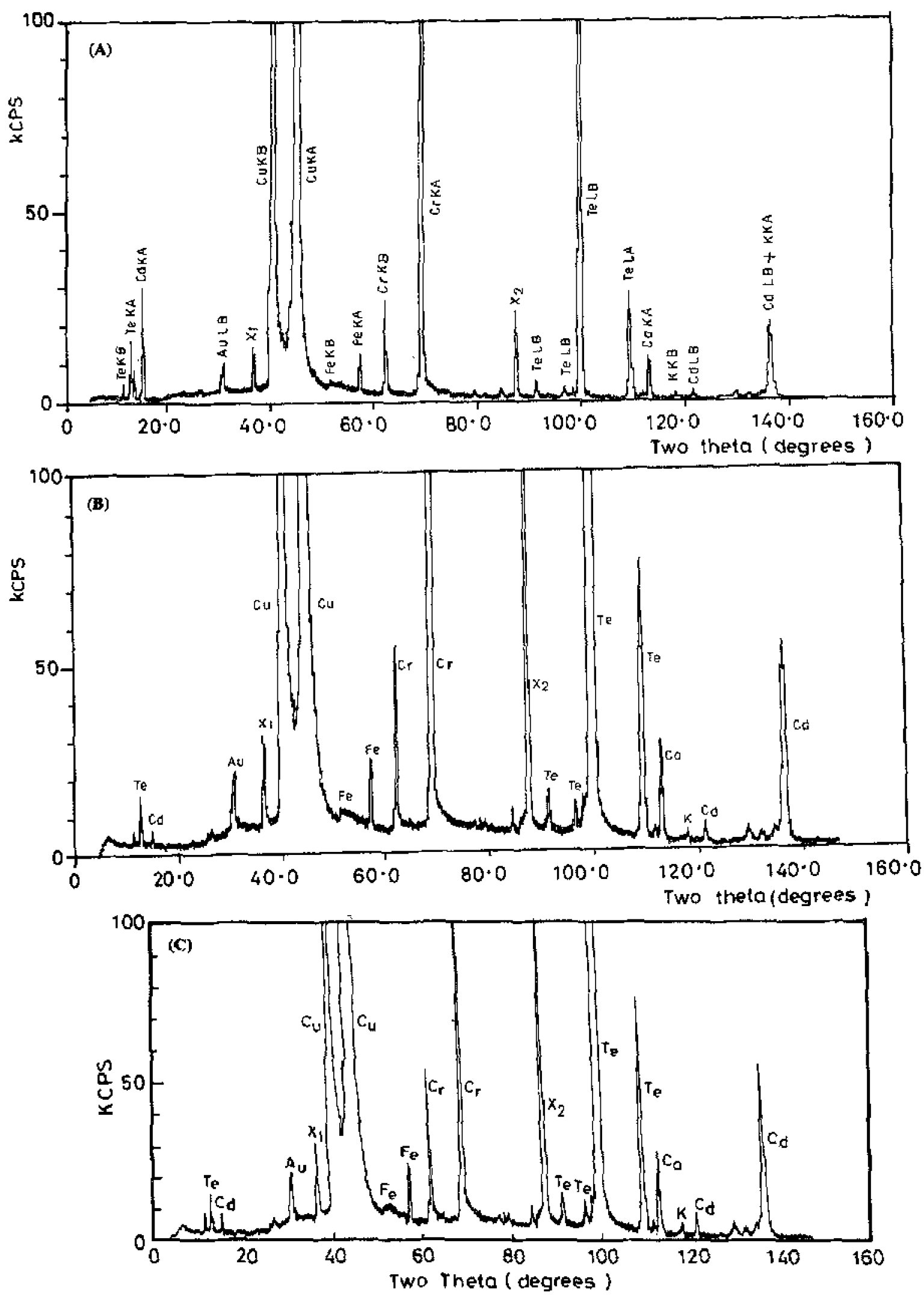

Figure 2. XRF spectra of CdTe films: (A) target material; (B) ri-sputtered film and (C) Cd-doped ri-sputtered film (Cr and Au from $X_{\text {-ray tube; }} \mathrm{Cu}$ line from mask; $\mathrm{Ca} \mathrm{X}_{1}$ urd $X_{2}$ may be instrumental errors). 
temperature legion was about $0.5 \mathrm{eV}$. This corresponds to impurity conduction due to excess cndminn. As the temperature is ratsed, the impurity levels are exhausted and the conduction becomes intrinsic in mature. The band gap obtained fron the slope at higher lomperature region was about $1.43 \mathrm{eV}$.

\subsection{Photoconductivity in CdTe films}

The variation of photocurrent with light intensity was recorded at room temperature. Photocurrent was observed to increase with light intensity showing saturation at higher light intensity as showll in figure 5 for two typical samples. The increase of photocurrent and decrease of resistivity with light intensity is due to generation of extra cartiets upon illumination. At lower intensities the concentration of available recombination centres is very nuch larger than the concentration of free electrons, most of the excited electrons have been trapped. Under this condition, the photocurrent varies linearly with light intensity. However, at higher illumination, generation of carriers are controtled by the recombination processes (Bube 1960).

The photoconductive rise and decay charactcristics of Cd-doped films at room lemperature were recorded with an $X-Y / t$ recordor. Figure 6 shows the rise and decay

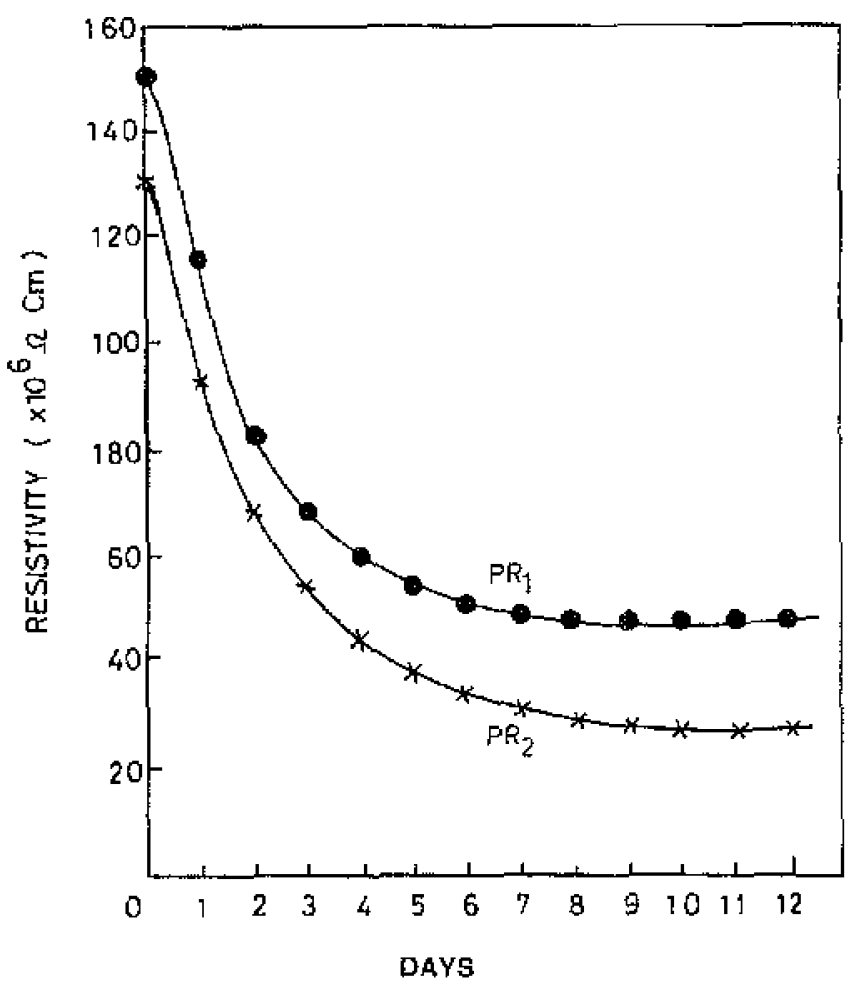

Figure 3. Ageing effect on resistivity of two typical Cd-cloped ColTe fiftns propared at $180 \mathrm{~W}$, doping concentration $2.6 \times 10^{14}$ $\mathrm{cm}^{-3}$ and gan area between eiectrodes $2.6 \times 10^{-2} \mathrm{~cm}^{2}$; thickness $9500 \AA$ (sample no. PR 1) and $10,000 \AA$ (sample no. PR2).

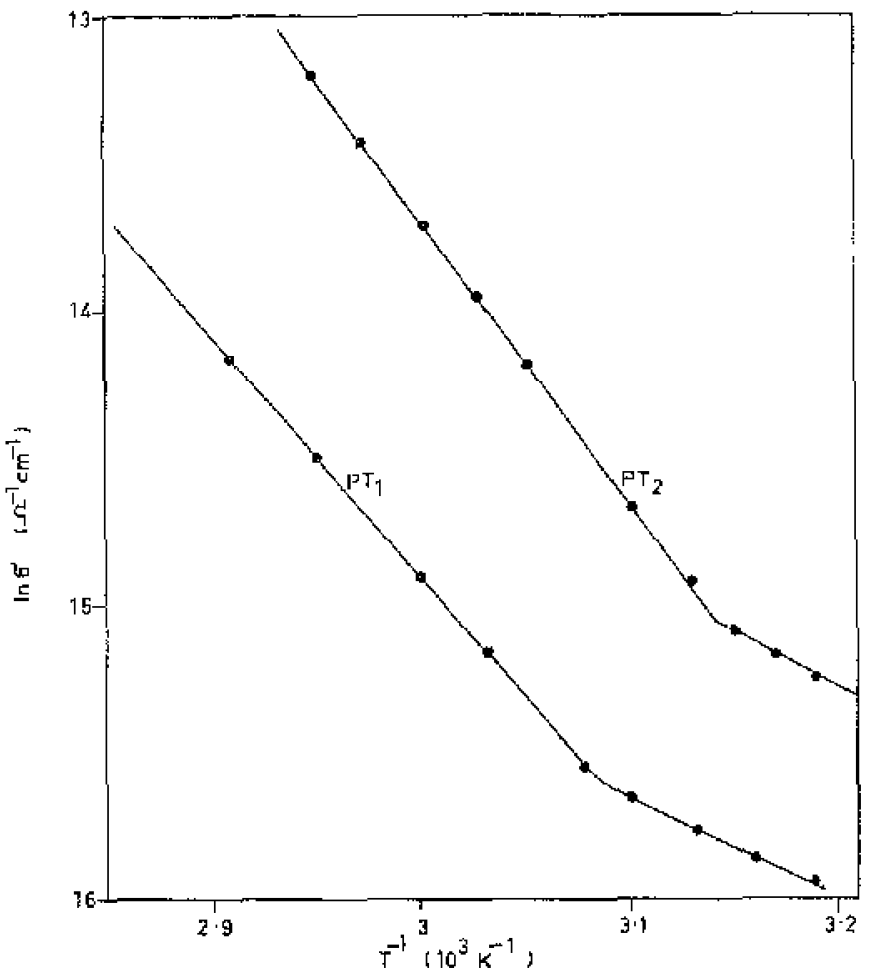

Figure 4. In $\sigma$ ys $T^{4}$ plots for two typical Cd-doped CdTe lilms preparcel at $180 \mathrm{~W}$. Sample PT 1 , gap type, doping conc. $6 \times 10^{14} \mathrm{~cm}^{-3}$; thick ness $11,000 \AA$, gap area $7.8 \times 10^{-2} \mathrm{~cm}^{7}$; sample PT2 stindwich type, doping conc, $3 \times 10^{14} \mathrm{~cm}^{-3}$; thickness $10,500 \mathrm{~A}$ : electrote aren $0.5 \times 10^{-2} \mathrm{~cm}^{2}$.

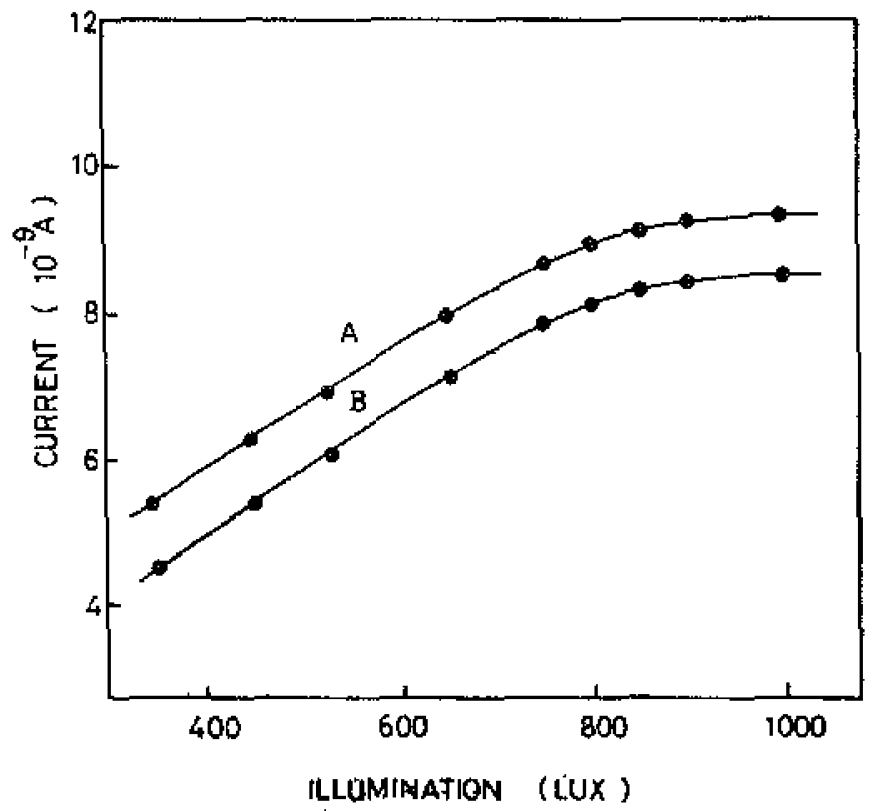

Figure 5. Veriation of photocurront with intensity of illumination for two typical films prepared at $180 \mathrm{~W}$; sample $\Lambda$. doping conc. $1.5 \times 10^{14} \mathrm{~cm}^{-3}$; thickness $12,500 \mathrm{~A}$; sample $\mathrm{B}$, doping conc. $6 \times 10^{13} \mathrm{~cm}^{-3}$. thickness $10,200 \mathrm{~A}$. 


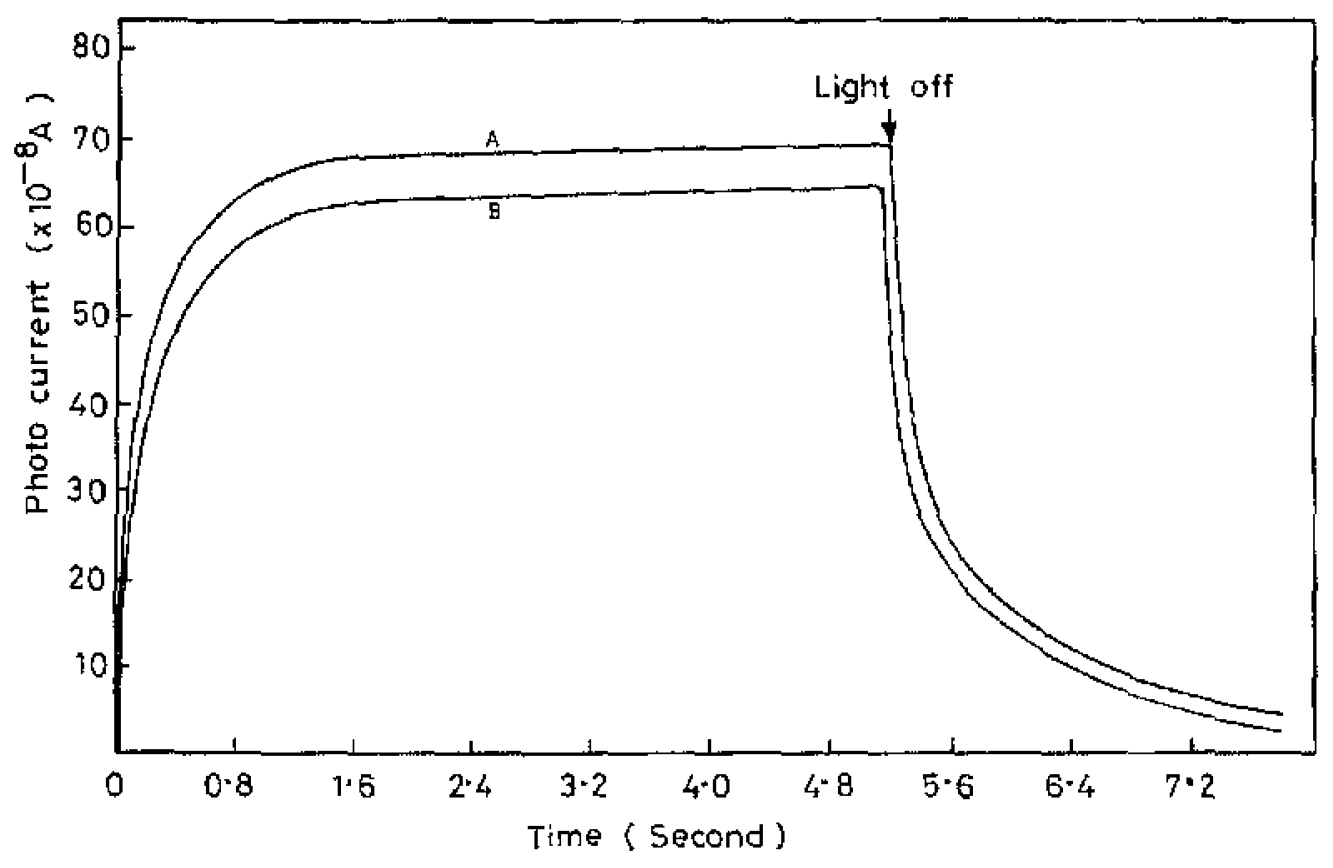

Figure 6. Rise and decay of photocurrent with time at $300 \mathrm{~K}$ for a typical $\mathrm{Cd}$-doped film. A, $500 \mathrm{Lx} ; \mathrm{B}, 1000 \mathrm{Lx}$ (rf power $180 \mathrm{~W}$; doping conc. $2.5 \times 10^{14} \mathrm{~cm}^{-3}$; gap area $2.5 \times 10^{-2} \mathrm{~cm}^{2}$ ).

curves of a typical sample. The rise and decay processes are characterized by initial fnst rise and slower decay. The rise and decay curves can be explained on the basis of release of electrons and holes under the influence of light accompanied by their recombination. The current reaches a steady value when the rate of recombination becomes equal to the rate of generation of new carriers and the concentration of carriers reach a steady value. When light is switched off, the initial rapid drop of photocurrent is controlled by recombination mechanism alone and depends on the life time of the majority carriers. However, at higher illumination the number of free carriers are higher than the trapped carriers and recombination takes place without involving trapping process (Bube 1960).

The photoconductive rise time $t_{\mathrm{T}}$ and decay time $t_{\mathrm{d}}$ were determined from the tingents to the rise and decay curves. The values have been observed to decrease with increase of illumination. The photoconductive decay curve has been found to fit the expression

$$
I_{\mathrm{pt}}=I_{00^{t}} t^{-b}
$$

where $I_{0}$ is the initial photocurrent at $t=0$ and $J_{n}$ the photocurrent after time $t$ and $b$ the decay constant.

Two plots of log photocurrent va log time of photoconductive decay at two intensilies of illumination for a typical sample is shown in figure 7 . For each illumination two linear regions are obtained giving two decay

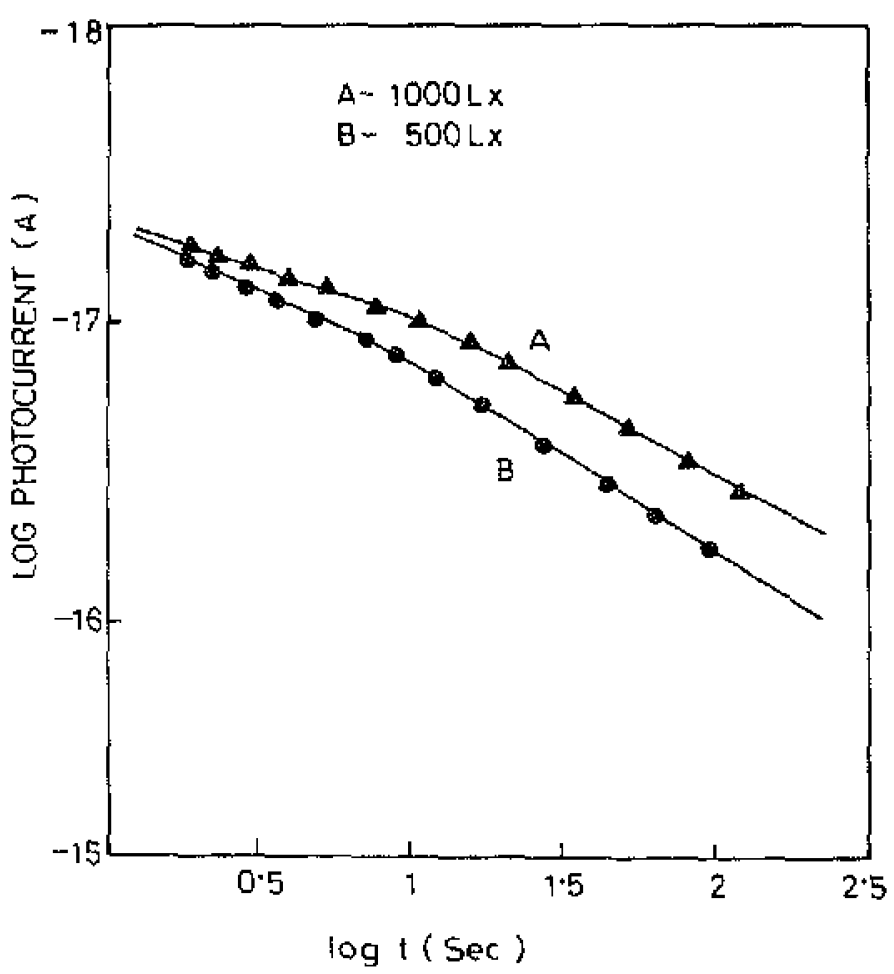

Figure 7. In photocurent vs in time plots for photocondnetive decny of a typical Cd-doped CdTe tilm prepared at rf power $180 \mathrm{~W}$; doping cont. $2 \times 10^{14} \mathrm{~cm}^{-3}$; thickness $10,500 \AA$; gan. area $2.5 \times 10^{-2} \mathrm{~cm}^{2}$ 
Table 1. Values of photoconductive rise and decay limes and decay constants of a Cd-doped sample at two intensities of illumination.

\begin{tabular}{|c|c|c|c|c|}
\hline \multirow{2}{*}{$\begin{array}{l}\text { Intensity of } \\
\text { illumination (Lx) }\end{array}$} & \multirow{2}{*}{$\begin{array}{l}\text { Rise } \\
\text { time } \\
t_{\mathrm{r}}(\mathrm{s})\end{array}$} & \multirow{2}{*}{$\begin{array}{l}\text { Decay } \\
\text { line } \\
\text { tid }(s)\end{array}$} & \multicolumn{2}{|c|}{ Decay constants } \\
\hline & & & $b_{1}$ & $b_{2}$ \\
\hline 500 & $0 \cdot 12$ & 0.20 & 0.37 & 0.58 \\
\hline 1000 & $0-08$ & 0.16 & 0.56 & 0.68 \\
\hline
\end{tabular}

Sample no. PO6. thickness $11,500 \AA_{+}$rf power $180 \mathrm{~W}$, gap area $2.5 \times 10^{-2} \mathrm{~cm}^{3}$, doping encentation $12 \times 10^{1.4} \mathrm{~cm}^{-3}$.

constants. They are observed to increase with illumination. The values of photoconductive rise time, decay time and the decay constants are given in table 1 . The photoconductive response has been observed to be slightly lower in sandwich-type sample thar in gap-type sample. This is possibly clue to interception of illuminated light by indium electrode in sandwich-type sample.

\section{Conclusions}

Some propertics of rf-sputtered Cd-doped CdTe films bave been presented here. Doping of CdTe tilms by $\mathrm{Cd}$ from a number of pellets on the CdTe target during sputtering, can be achieved up to $10^{14} \mathrm{~cm}^{-3}$. The films are found $n$-type and endowed with defects as indicated by the aging effect on resistivity. The resistivity of the films decreases very fast initially after the preparation of the samples and then slowly attaining a constant value after about 8 days. Temperature dependence of dark conductivity shows that conduction between roon temperature to $338 \mathrm{~K}$ is mainly due to impurity levels, activation energy being about $0.5 \mathrm{eV}$. At higher temperature beyond $338 \mathrm{~K}$ the conduction becomes intrinsic showing a band gap of about $1.43 \mathrm{cV}$. The photocurrent has been observed to increase rapidiy with illumination at lower values and tends towards saturation at higher values. The photoconductive tise and decay curves have been found to decrease while decay constants increase with illumination.

\section{Acknowledgement}

The authors wish to thank the Department of Science and Technology, New Delhi, for using the equiprants procured for a different project funded by them.

\section{References}

Bube R H 1960 Photoconductivity of solids (New York: John Wiley and Sons, Inc.)

Buncrjee $A$, Sath $\mathrm{H}$ and Guba $\mathrm{R}$ 1989 Indian I. Phys. A63 326

Basol B M 1988 Solar Cells 2369

Das S R and Cook I G 1988 Thin Solid Films 163409

Fisher $\mathrm{T} F$ and Weber $\mathrm{C}$ E $1952 \mathrm{~J}$. Appl Prys: 23181

Gogoi $S$ and Banza K 1982 Thin Sold Films 92227

Matsumolo $H$, Kuribayashi $K$, Uda $H$, Komatsa $Y$, Nakano A and Jkcgeni S 1984 Solar Cells 11367

Mitchell K W, Eberspacher C, Cohen F, Avery J, Durn G and Botlenberg W 1985 Proc $18 \mathrm{th}$ IEEE PVSC Las Vegas, NV (New York: IEEE) p. 1359

Rhoderik E H 1978 Metal-seniconductor contarts (Oxlord: Clarerdon Press) p. 54

Rose M R, Lowrence A S and Wulf J 1987 Electronic properties of matter (New Delhi: Wiley Eastern Lid, p. 144

Sarmah P C and Ratman A 1990 Intian J. Phys. 16421

Sheer J J and Yan Laar J 1961 Phillip. Res. Rep. 16323

Uda H, Taniguchi H, Yoshida M and Yamashita T $1978 \mathrm{Jap}$. J. Appl. Phys, 17585

Zanio $K_{1}$ Willardson R F and Beer A C (eds) 1978 Semiconductors and senimetal" (New York: Academic Press) 13164 